\title{
Creating Ethical Research Partnerships - Relational Accountability in Action
}

\author{
Robert Henry, Caroline Tait, STR8 UP
}

\begin{abstract}
Research that focuses on Indigenous street gangs is primarily derived from the experiences and expertise of individuals who work in the criminal justice system or community-based organizations and not street gang members themselves (Grekul \& LaRocque, 2011). The primary reason for this is that it is difficult to build research relationships with individuals who, for the majority of their lives, have tried to keep their lives hidden from those who they consider as outsiders. However, it is these narratives of those who have been directly involved with street gangs that provide the greatest insight into what attracts individuals to join, the realities of street gang life, and what is needed to support individuals to exit street gangs. The current article examines how relational accountability framed within the 4Rs (Kirkness \& Barnhardt, 1991) was used to engage in a photovoice research project that focused on how Indigenous male ex-gang members came to construct their notions of masculinity within local street gangs. To engage the men in the research, relationships were built with STR8 UP, a community-based gang intervention program located in Saskatoon, Saskatchewan. By building relationships, the foundational components to Indigenous research, trust between researcher and participants was established where modifications within the research methods could occur to engage the men's participation more fully. The current article also examines the importance of critical reflexivity within relational accountability, as it provides researchers with a tool to understand their social privileges and how this can impact the research process
\end{abstract}

KEYWORDS Relationality; participatory research; photo voice; Indigenous street gangs

"I got lost in the wild, the wild people took me in and helped me, made me their king, and I lived to tell civilization about it."

Victor Rios, Punished: Policing the Lives of Black and Latino Boys

We begin with words from Victor Rios who challenges researchers, specifically those who conduct research with street gang members, who continue to maintain the "saviour trope," in which outsiders - in particular "rogue sociologists" - enter into a mysterious land or environment and through their own strong will and determination, emerge to tell the story of the "other." Rios explains that "this self-aggrandizing narrative, perpetuate[s] the flawed 
policies and programs and public understanding[s] of the urban poor as creatures in need of pity and external salvation" (Rios, 2011, p. 14). This holds particularly true within the history of Western colonial research on Indigenous peoples, in which Indigenous peoples and cultures are placed under a microscope to be deconstructed, defined, and positioned as the "Other" (Smith, 1999; Louis, 2007; Brooks, Poudrier, \& Thomas-MacLean, 2008; Wilson, 2008; Kovach, 2009; Absolon, 2011). To challenge dominant forms of research practices that position the research as superior and those under study as lacking knowledge, researchers who intend to conduct research with and within Indigenous communities must engage in a relational research process, one that is built on Indigenous concepts of relationality (Wilson, 2008) with the intention of creating decolonial spaces to improve relationships between Indigenous and non-Indigenous communities and peoples.

Our intentions here are to show the importance of relational accountability and its application in a photovoice research project that focused on Indigenous ex-gang members. We explain the importance of relational accountability, framed by Kirkness and Barnhardt's (1994) 4Rs - respect, relevance, reciprocity and responsibility - for researchers. Reflexivity is central to the process, since at all stages, researchers and their partners must become consciously aware of their cultural capital and its impact on the research process. It is through this process, or relational accountability, that agency can be acknowledged and research methods can be modified to fit the social realities of the participants and community.

To show how relational accountability can be fostered within research projects, we focus on research conducted with the authors and their community partner. We explain how relationships became the foundation for research to be conducted with Indigenous men who were at one time involved in the street gang lifestyle. We begin by discussing the important effect that community partnerships and collaborations have on the active engagement of participants. We follow this with a description of the research framework- the 4Rs-which is needed to strengthen relational accountability (Kirkness \& Barnhardt, 1994) and to move research forward in an ethical way. (Louis, 2007; Wilson, 2008; Absolon, 2011).

\section{Getting Started - Utilizing Prior Relationships for Recruitment}

A primary issue for street gang researchers is to find participants who are willing to partake in the research process. Much time and many resources are often needed to build trust with street gang members; the researchers have to prove that they are not there as undercover informants searching for information against individuals (Bourgois, 2009; Vanketesh, 2009). Some researchers use prior relationships with individuals from their old neighbourhoods, whom they have met before (Rios, 2011). Most researchers, though, recruit participants through organizations (criminal justice and community-based) that work directly with street gang members (Grekul \& LaBoucane-Benson, 2008; Garot, 2010). For this study, a partnership was created with the community-based organization STR8 UP. STR8 UP is a not-for-profit, nongovernmental organization that supports individuals as they try to remove themselves from gangs and the street lifestyle. STR8 UP's mission statement states:

Engaged Scholar Journal: Community-Engaged Research, Teaching and Learning 
STR8 UP assists young men and women to master their own destiny in liberating themselves from gangs and criminal street lifestyles. STR8 UP builds healthy families and endeavors to provide individuals and their families with the skills and resources they need to become responsible citizens which will lead to a positive and gang free lifestyle. (STR8 UP, 2012, p. 1)

STR8 UP strives to provide support through outreach and connecting members with other community organizations. STR8 UP has built strong relationships within the core neighbourhoods of Saskatoon and other smaller First Nations communities in Saskatchewan through their outreach work and presentations to educate people about the realities of the street gang lifestyle.

STR8 UP was founded in 1998 when some Indigenous men in the Saskatoon Correctional Centre (SCC) approached Father André Poiliévre, at the time the centre's chaplain, for advice on how to get out of their gangs. At the time, there were no programs in Saskatoon that provided interventions for individuals who were trying to exit their street gang. As Father André stated during a conversations about the history of STR8 UP:

I remember two guys came up to me and I knew they were active gang members. We had talked and they had indicated that they wanted out. I don't remember the occasion, the time, the details, the circumstances, except that they were struggling with it. And so this other guy came up to me and says, "If he leaves, I leave, but we don't know what to do. We don't know anybody that's left, we don't know what happens." So that's where it started. I just said, okay, let's work at it.

With a high Indigenous membership, STR8 UP incorporates Indigenous perspectives and concepts into its programming. STR8 UP focuses its programming around a Medicine Wheel framework which symbolizes the four aspects of self-mental, physical, emotional, and spiritual (King, Smith, \& Gracey, 2009). As Marlene Brant Castelleno (2000) explains: "The [M] edicine [W] heel teaches us to seek ways of incorporating the gifts of the other quadrants. It encourages us to bring more balance to our own lives or and to form relationships and work in teams." (p. 30). The Medicine Wheel is used to help STR8 UP members frame their journey of recovery and healing by balancing the four aspects of self and contextualizing how an individual moves through the different phases of life, i.e. child, youth, adult, elder.

STR8 UP encourages its members to talk about their experiences. To create a platform, STR8 UP asks its members to take an active participatory role when they go to speak to schools, programs, and organizations about the street gang experience. As Dave (27, STR8 UP member) explained:

I went for coffee with him and he was like, "Do you want to come and see what we do?" So, I went to it and he did his little spiel on STR8 UP, did his whole demonstration and wrote everything out on the white board for me and I was like, holy s***! This guy understands-for the first time, somebody actually made sense of everything. 
I actually spoke at that one, because I saw all those kids sitting there; I never, ever thought that I'd be talking to kids? I was seeing all those kids there... see I could just see it, you could just see it in kids' eyes, man. You can just see the hopelessness sometimes. But in any case, that's the start of STR8 UP for me. For the next year and a half, I didn't miss one presentation. I didn't care if I have to walk to it. I was getting there. And with the support of this thing, I am where I am today.

Such experiences are important as they provide members the opportunity to build connections with other members and share their experiences as a way to give back to the community.

As in the STR8 UP model, the building of relationships was central in the research process for our project. Because relationships were important, we adopted a flexible methodological approach, modifying methods to support the current realities of the participants. For example, some of the men were living healthy, stable lives, while others had just exited correctional institutions and were dealing with addictions, mental health, poverty, housing, and street violence. Therefore, some individuals had opportunities to move more easily in and out of the community, while others needed transportation support. STR8 UP supported the project and provided transportation for individuals to come to interviews. Although relationships were important, we also had to recognize that visual research (photos, videos) could enforce negative stereotypical perceptions of Indigenous men, violence, and street gangs.

\section{Ethical Photography - Breaking the Colonial Lens}

The capturing of Indigenous peoples in their "natural state" through photographs has had a long and often troubled history in Canada. Late nineteenth- and early twentieth-century photographers such as Edward Curtis set out to photograph Indigenous peoples with the intention to photograph the "features of the Indian life and environment-types of the young and the old, with their habitations, industries, ceremonies, games, and everyday customs" (Vervoort,

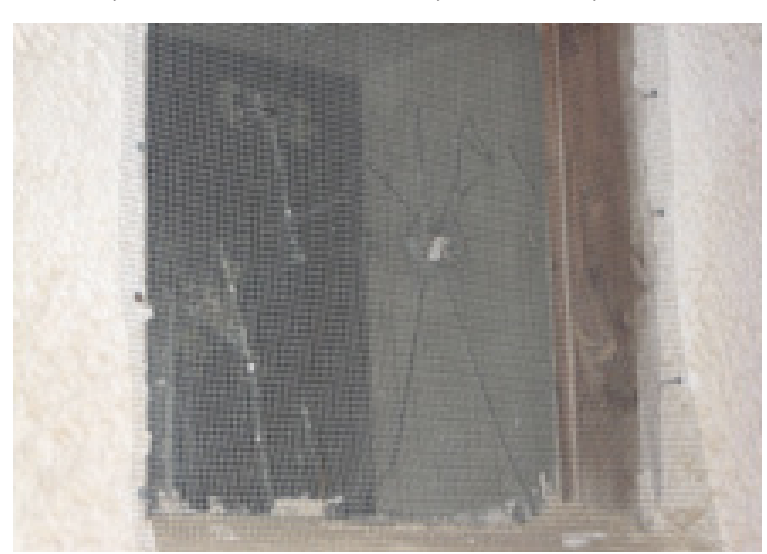

Figure 1: Bones took me to a now abandoned apartment building that he and his gang used to hang out in. He talked about one night where gunshots were fired in the building and went through this window. 2004, p. 464). Daniel Francis (1992) describes how the Canadian Pacific Railway (CPR) used photographs of Indigenous peoples to create a specific experience of the "West" to promote tourism. The most sought-after photographs depicted Indigenous peoples in "traditional clothing," or partaking in "traditional activities." To support the consumer appetite of the travelling settler, most photographs were staged, as Indigenous peoples were instructed by white photographers to wear traditional regalia and remove anything European (i.e. clothes and 
tools). Such staging helped to maintain the nostalgic colonial ideology that that Indigenous peoples could not change or adapt to European culture (Francis, 1992). Through the staging of photographs, the CPR and their photographers reinforced the colonial gaze; clearly the civility of Europeans was needed to tame the "Wild West" (LaRocque, 2010). As a result of this history, photo-based research with Indigenous peoples must avoid marginalizing Indigenous peoples even further through photographs, particularly of those seen to occupy the edges of "civil" society (Castleden et al., 2008). Although such concerns are valid, visual research has great potential in Indigenous research methodologies.

The use of photographs and other visual methods as qualitative research tools is relatively new in research of street gangs (Kontos, Brotherton, \& Barrios, 2005); however, photographs in research such as photo elicitation have been widely used by anthropologists and sociologists since the turn of the twentieth century. Researchers at this time used photographs as a way to elicit longer and more comprehensive interviews with individuals, in cases where cognitive delays and language were barriers (Harper, 2002). However, the importance of photographs was secondary to the research process and methodology when results were published. As Castleden et al. (2008) state:

Photography in academic research is not a novel approach. It has been an accepted tool in fieldwork practice since the 1920's... While visual data is increasingly recognized as an effective method for shared interpretation in participatory research, references to photography in academic literature remain sparse. (Davidson, 2002, p. 1395).

With a lack of academic literature on photography as a research process, traditional qualitative and quantitative research methods are still preferred, specifically with street gang research. This is troublesome because photographs can enhance the research process and provide researchers with a visual pathway to support the perceived realities of those involved, or who have been involved, with street gangs.

For this project, photovoice methods were used to understand the experiences of the participants. Caroline Wang and Mary Ann Burris describe photovoice as a "process by which people can identify, represent, and enhance their community through a specific photographic technique" (1997, p. 369). Most commonly, participants are asked to portray their knowledge of aspects of health through photographs (Wang \& Burris, 1997; Wang, 1999; 2003). The intention is to provide marginalized populations the opportunity to capture images from their perspectives and reflect on them, thus acknowledging them as experts on their own realities (Wang \& Burris, 1997; Castleden et al., 2008; Mitchell, 2011). Photovoice research then is a transformational research approach that allows researchers to learn from those most impacted by the experience, as participants give researchers and the broader community a reflection of how they view the experience under study.

The importance of photovoice is in its focus on transformational methodology (Friere, 1970), in which participants become active agents in the research process and are situated as the experts of their own lives (Wang \& Burris, 1997; Castleden et al, 2008). Although research 
ethics involving Indigenous peoples of Canada have shifted, with the creation of OCAP (Ownership, Control, Access, and Possession) and Tri-Council Policies for Indigenous research partnerships, Indigenous voices continue to be silenced due to systemic power structures (i.e. continued colonial policies) of exclusion (Spivak, 1988; Smith, 1999; Koukkanen, 2007; Blodgett et al., 2011). Photovoice methods shift traditional research ideologies by creating an opportunity for those people most affected within a phenomenon to become actively engaged in the research process (Wang, Cash, \& Powers, 2001; Wang, 2003; Brooks, Poudrier, \& Thomas-MacLean, 2008). Through reflexivity, photovoice methods can then be used as a tool to support Indigenous male ex-gang members as they reflect back on their life history and the connections to masculinity, identity, and street gangs.

However, caution is needed when working with vulnerable research participants, as visual representations can be double-edged. For example, images can inadvertently reproduce commonly held stereotypes or prejudices of the community being represented (Daniels, 2008; Mitchell, 2011). To limit misrepresentations, participants must be included in the dissemination of any photograph that they personally take. If ethical protocols and reflexivity are ignored during the research process, the photographs taken of or by marginalized participants can be used to reproduce socially constructed stereotypes (Daniels, 2008).

\section{Research Framework - Relational Accountability, Ethical Reflexivity, and the 4Rs}

Historically, research and science have often been used to enforce oppressive ideologies over Indigenous peoples and support colonial occupation and control (Smith, 1999; Brown \& Strega, 2005; Denzin, Lincoln, \& Smith, 2008). For example, during the Enlightenment period in Europe, craniometry was used to support the racialization and poor treatment of nonwhite Western Europeans by quantifying particular skull characteristics supporting a hierarchy of intelligence (Omi \& Winant, 1993; 2014). Through “objective science," doctors would skew results when they challenged the social understandings of civility and intelligence (Omi \& Winant, 1993; 2014; Dei, Kumanchery, \& Kumanchery-Luik, 2004). Thus, craniometry rationalized Western colonial ideologies of racial superiority to control Indigenous peoples and resources.

Research through an "Imperial gaze" has impacted colonial relationships between Indigenous and settler peoples (Smith, 1999; LaRocque, 2010; Razack, 2015). In Canada, much research with Indigenous peoples has and continues to be framed through Western colonial lenses, limiting Indigenous knowledge and contributions to the research process (Brant Castelleno, 2004; Alfred, 2005; Kovach, 2009; Absolon, 2011). Because colonization is imbedded in Canadian social systems, i.e. justice, health, education, research is often used to support neocolonial policies to control Indigenous peoples and their movement (Koukannen, 2007; Sinclair \& Grekul, 2012; Razack, 2015;). Research by Frances Widdowson and Albert Howard (2008), and Tomas Flanagan (2008) on economic and policy development, and Mark Totten's (2010) work on Indigenous street gangs have been used to influence policies that negatively impact Indigenous peoples. For example, Mark Totten has attempted to create linkages among three social issues-fetal alcohol spectrum disorder, gangs, and 
sexual exploitation of Indigenous men and women-with little evidence to support such claims (Henry, 2013); however, because these linkages are already present in the Canadian consciousness about Indigenous peoples, they are easily accepted as truth (Henry, 2013). News media outlets then use this "research" and create stories that connect tragedies of Indigenous peoples in communities to street gangs and the overall ill health (predominantly mental health, i.e. addictions, substance abuse, violence, etc.) of individuals and the community to their own poor choices, with little space to assess the impacts of colonization on Indigenous peoples and communities (Razack, 2015).

So how can researchers challenge the imbedded socialized perceptions of those living in marginalized spaces? And how can researchers and their collaborators work together to decolonize and create an agency of change that reflects the realities of those who are most impacted? It is here where we turn to the importance of relational accountability in the research process.

\section{Relational Accountability - Relationality and Community-Based Indigenous Research}

Relationality or relational accountability is an important concept in many Indigenous communities (Louis, 2007; Wilson, 2008; Absolon, 2011; Macdougall, 2011). It is grounded in Indigenous epistemologies in which researchers position themselves within a larger web of relations to their environment and research partners (Simpson, 2000; Grande, 2004; Kovach, 2009; Hart, 2010; Macdougall, 2011;).

It's collective, it's a group, it's a community. And I think that's the basis of relationality. That is, it's built upon the interconnections, the interrelationships, and that binds the group...but it's more than human relationships. And maybe the basis of that relationship among Indigenous people is the land. It's our relationship to the land. There's a spiritual connection to the land. So it's all of those things. (Wilson, 2008, p. 80)

According to Wilson, relationality is complex and is the interconnected space where individuals come to understand their cultural capital and how they are to act within local codes (see also Bourdieu, 2001).

Notions of interconnectedness are also emphasized by Brenda Macdougall's (2011) research on familial histories of Métis peoples in northwestern Saskatchewan. She explains that, through the Cree word wabkootowin, Métis peoples maintained an identity and familial relationships across cultures, communities, environments, and time:

In short, this worldview, wahkootowin, is predicated upon a specific Aboriginal notion and definition of family as a broadly conceived sense of relatedness with all beings, human and non-human, living and dead, physical and spiritual... Identity, in this conceptualization, is inseparable from land, home, community, or family. They are all one and the same. (p. 3) 
Relational webs must be carefully understood and navigated accordingly to construct ethical research space within Indigenous communities. The processes to engage communities in research differ depending on the community and the relationship with the researcher. For example, prior to conducting any research, some researchers who have worked in Indigenous communities have participated in spiritual ceremonies such as a pipe ceremony or a sweatlodge (O’Rielly-Scanlon, Crowe, \& Weenie, 2004); some spend the first part of their research speaking with the community members and creating relationships prior to conducting any research (Innes, 2009; Castleden, Morgan, \& Lamb, 2012); while others use community connections or "gatekeepers" to help navigate the research in the community (LaVeaux \& Christopher, 2009). Whatever the process, researchers must be willing to abide by and respect the community's wishes to forge ethical research relationships.

Due to the precarious conditions of the lives of the men, prior relationships between Father André Poiliévre (founder), Stan Tu'Inukuafe (STR8 UP coordinator) and the researchers were essential in the recruitment of the research participants. Both men are respected by STR 8 UP members and others living a street lifestyle in Saskatoon. It was through relationships with them that trust would be built with STR8 UP participants. The approval of the project by Father André and Stan encouraged some STR8 UP members to participate in the project. Therefore, André and Stan could be viewed as gatekeepers (LaVeaux \& Christopher, 2009), since it was through their recognition, approval, and recruitment of participants that the researchers gained access to a cohort of men involved in street gangs. While gatekeepers can provide the connections, it is up to the researchers to build the relationships. This is very often difficult to do when working with marginalized populations, as it takes a lot of time and energy on the part of the researcher to break down personal and social perceptions that could be potential barriers to the research process.

To break down socially constructed barriers caused by colonization, researchers must first be able to listen to Indigenous partners. This means that open conversations need to occur before researchers can understand what barriers might hinder the research process and think of ways to adjust research methods for full engagement. Conversations held with Father André, Stan, and some of the participants prior to the research commencing aided in creating an ethical space to discuss issues of concern. As Ermine (2007) states:

The sacred space of the ethical helps us balance these moral considerations as we discuss issues that are trans-cultural, or trans-boundary in nature... With this notion of ethics, and juxtaposed on the broader collective level, we come to the inescapable conclusion about our own agency in the kind of civilization we create to live in. (p. 196)

It is within Ermine's concept of ethical space that researchers must begin the difficult process of reflexivity and learn how one's unearned privileges impact the research process.

To construct ethical space in the research process, researchers must engage in a critical reflexive consciousness to understand how their social identities shape the researcher/ 
participant relationship. Since research is never truly objective, researchers must learn to unpack their cultural baggage to understand how they have come to interpret their worldviews (Friere, 1970; Kleinman, 1977; Bourdieu, 2001; Nussbaum, 2015). Such positioning is important in gang research because poor and ethnic minority youth are constructed as de facto status (Cacho, 2012) gang members as a result of their social identities (White, 2009; 2013). To challenge this subjectivity, researchers must use a critical self-reflective gaze in order to understand how their epistemologies, ontologies, and axiologies shape and affect the research process (Wilson, 2008). Critical self-reflection allows researchers to acknowledge how their unearned privileges, i.e. whiteness, have come to shape their knowledges and perceptions of truth (Friere, 1970; Louis, 2007).

By working from places of humility and honesty (two core values of STR8 UP), the participants and Robert constructed ethical researcher/participant relationships. To begin with, Robert opened up about his past and the intentions of the project. He engaged in critical self-reflection on his privileged status, beginning every session by talking to the participants about how he came to be conducting research on Indigenous street gangs. The intention of the conversations was to create relationships through noting the similar experiences that Robert may have had as a Métis living in Prince Albert and the participants themselves may have had. Relationships became central to the research process, as STR8 UP members could ask questions or voice concern about the project or Robert's intentions.

Through critical self-reflection, researchers can work to dismantle and decolonize what they have taken for granted as a result of their privilege. The result is a broader ethical research framework of relational accountability that is built from respect, relevance, reciprocity, and responsibility. The result is the construction of a web, where if one section is weakened, the research loses its connection to community agency.

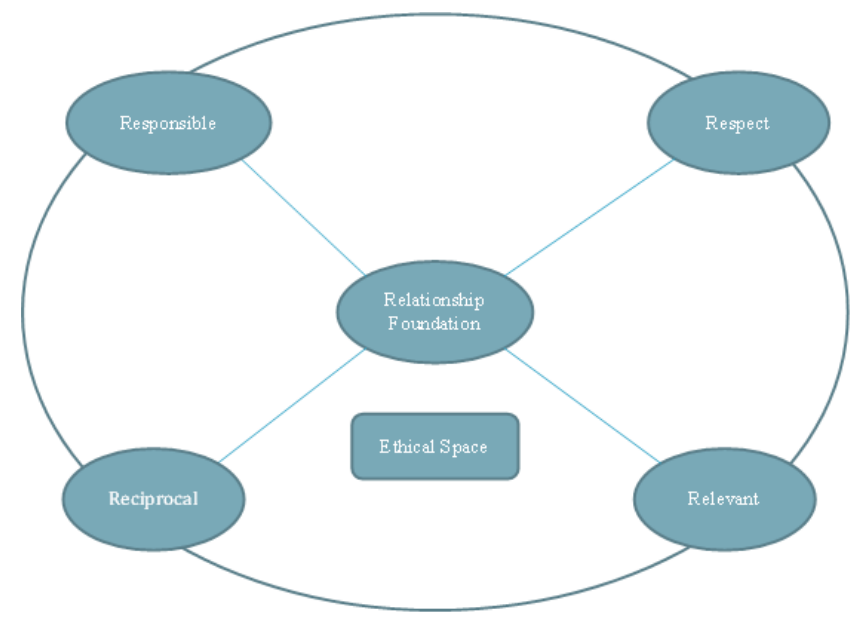

Figure 2: Relational Accountability Model 
It is within this framework that relational accountability is able to strengthen the research process. The model is not designed as a step-by-step process; rather, depending on the research relationships already in place, different researchers may choose different starting points. For example, those researchers who have a history of doing creditable research with community partners may engage at the point of relevance, because they have a level of respect from the community from previous work. It does not matter where one begins; for the relationship to strengthen, all four sections of the outer circle must be addressed. If not, the relationship will cease to move forward and the research process will halt or become difficult to complete. For our intentions, we began with the concept of respect and worked clockwise, because beginning researchers need to prove their intentions first of all and then build trust with their new community partners.

\section{Respect - You Get What You Give}

Respect within the research process is fundamental to strengthening, nurturing, and cultivating relationships (Kirkness \& Barnhardt, 1991). Because respect is earned on the street through violent actions, STR8 UP works with its members to redefine respect in a positive way. For example, there were times in the men's lives when respect meant enacting violence to gain respect through fear. Adam (36) explained:

It seemed like everybody respected you because you got in a fight, you stabbed somebody, you robbed somebody. You know women look at that being like a gangster...the worse I got, the more friends I had.

There were other times, when the condition of being respectful or respected was demonstrated through one's ability to care and nurture in reaction to a traumatic event. As Dwayne (29) explained:

I was bleeding and they were dragging me by my hair. They pulled my braid out, hitting me and I was bleeding. I don't know where this Native guy came from. He was an adult and he picked me off the ground and I was bleeding and crying. I don't know who he was; but I have nothing but respect for him. I'll never forget what he told me. He said never to let anyone take my pride away. Be proud of who you are; be proud of being Native. Your hair is beautiful.

These are two examples of how respect was shown or earned in the lives of the men. An individual felt himself respected when he committed violent acts, yet respected others for their compassion for those who were victimized.

Within academic contexts, respect may have different meanings, as Rauna Kuokkanen (2007) cautions:

In academic contexts, respect is often reduced to mere tokenism or, even worse, empty rhetoric...Mere respect tends to create a climate of "repressive tolerance" in 
which [1]ndigenous people[s] and their epistemes are allowed to exist in the celebratory spirit of different perspectives or points of view but are not recognized, heard, or understood except superficially and relativistically. (p. 79)

Because of the potential for tokenism and empty rhetoric, respect as a concept must be explained as it can have different meanings for different people involved in the research process.

Within the research field, a researcher's actions or non-actions can affect the research process. If individuals lack respect for one another, then people will find ways to create barriers making the research process difficult to undertake, complete, or not begin at all. Thus, respect is earned and measured based on one's trust of the other. Respect in research occurs when those involved understand the goals, objectives, and one another's roles in the process. According to Renee Pualani Louis (2007):

\begin{abstract}
Respect is not just about saying "please" or "thank you." It's about listening intently to others' ideas and not insisting that your ideas prevail (Steinhauer, 2002, p. 73). It's about displaying characteristics of humility, generosity, and patience with the process and accepting decisions of the Indigenous people in regard to the treatment of any knowledge shared. This is because not all knowledge shared is meant for a general audience. (p. 133)
\end{abstract}

If researchers do not respect their partners, then the relationships built will be strained or broken, leading to disengagement from the research process (Smith, 1999; Castleden et al., 2008; Absolon, 2011).

To build respect with the men, listening became central to the process. It allowed researchers to understand possible social barriers that could impact the research process. For gang research, this means that researchers be open-minded and not pre-judge gang members as "bad people." For many, this is difficult because of the violence and trauma that they have inflicted on others; however, through becoming learners in the research process, researchers can slowly comprehend why the men made such decisions. This respectful learning position gives researchers the opportunity to make connections to the larger socio-political histories of colonization and their impact on available choices.

Over the course of the data collection, engagement with some men focused strictly on talking about their experiences through one-on-one interviews. Others needed support from both STR8 UP and the researchers who entered the community as they took photographs and talked about their different experiences and memories. The variance in how the interviews and data were collected shows the different levels of respect and trust that were built among some of the men. Through the acknowledgement and respect of the men's knowledge, and the shaping the research to help others, the men began to see the overall relevance of the research project to themselves and others. 


\section{Relevance-Making Research Worthwhile}

The construction of meaningful and respectful relationships can move discussions towards understanding the need and/or importance of the research for participants and the broader community (Koukkanen, 2007; Absol on, 2011). If a researcher is not from the community, sitting, listening, and speaking to community members will be a necessary process (Absolon, 2011). Questions such as "is the research important to the community?" "Is the community

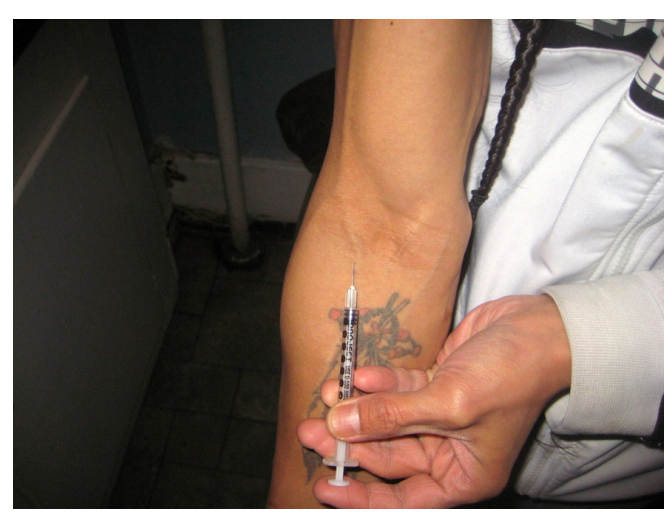

Figure 3: Bones talked about the trauma that he faced as a child, teen and adult. He explained that one way to deal with everything is to get lost in drugs. Through this photograph, Bones explains how drug usage became more difficult to escape because of the actual and perceived threat of violence. at a point that the said research can be undertaken?" must be asked to see if the research project is worth it or helps to improve the wellness of the community and members overall. Agency and research relevance can be established when the research methods and outcomes are made to fit the social realities of the community (Castleden et al., 2008). If the communities cannot see the benefit of the research, or resources are insufficient, or more pressing issues exist in the community, then the research becomes irrelevant.

Within the prairie provinces of Canada, Indigenous street gangs are regarded as a root cause of many criminal justice and health issues affecting Indigenous and non-Indigenous communities (Criminal Intelligence Services Saskatchewan, 2005; Grekul \& LaBoucaneBenson, 2008; Bracken, Deane, \& Morrissette, 2009; Comack, Silver, Morrissette, \& Deane, 2013). With little information on Indigenous street gangs outside of criminal justice surveys and annual reports in Canada, communities continue to look to American policies and utilize suppression strategies to target street gang activities and members (Grekul \& LaBoucaneBenson, 2008). For example, in the United States "gang sweeps" have become popular in urban centres as a way to "round up" potential and known gang members. However, rather than creating safety within the community, these sweeps create animosity between law enforcement and the peoples who are targeted, specifically black and Latino youth in impoverished neighbourhoods (Bjerregaard, 2003; Barrows \& Huff, 2009; Van Hofwegen, 2009). To avoid the increase of suppressive tactics in addressing Indigenous street gangs, comprehensive and relevant research is required to create a more accurate and broad understanding of the issues related to Indigenous street gang involvement.

With limited research on Indigenous street gangs, the information available does not reflect the historical and social conditions of those who are the most impacted by the gangs or the policies created to address them. As a result, the majority of prevention, intervention, and suppression programs continue to rely on positivistic criminological theories to frame street gang programs. Such programs focus on education or curriculum-based prevention to help 
individuals make the "correct" choice. The difficulty is that choices do not reflect the lived realities (Korp, 2008; Klein \& Maxson, 2010). Rather, education programs (i.e. Drugs and Alcohol Resistance and Education-DARE, and Gang Resistance, Education, and TrainingGREAT) have little impact on making a change in the lives of the youth that they claim to help (Klein \& Maxson, 2010).

To move beyond broad-based educational prevention approaches and suppressive policies that racially target communities, spaces need to be created to include the life histories of the individuals who have been involved in street gangs. Public presentations are a good way for individuals to have the opportunity to speak about their past and their present. Such approaches can be seen to follow Indigenous sharing circle models, restorative justice, and addictions programs (Alcoholics Anonymous), where individuals have the opportunity to share, be heard, and be respected. As a result, individuals have the opportunity to express themselves in a group setting, find support through other individuals who have shared similar experiences, (Lavallee, 2009) and educate others about the harsh realities of street gangs and the street gang lifestyle.

STR8 UP provides its members with the opportunity to present and talk to others through community presentations. All members are given the opportunity to speak to youth and the broader community to educate them through their own personal narratives. The men who participated in this study emphatically reiterated that this research would help them to share their narratives with others in the community. As Baldhead (24) states:

I can get on so many different stories to talk to a specific group...addiction, gang prevention, drug and alcohol awareness for the youth at-risk, I can get on different topics. I started telling my story to people and I started to see what it was doing for people...kids started coming up to me from the streets...telling me their problems and stuff like what they are going through with school and stuff. I noticed that I started making an impact on kids and kids were coming up to me asking me for advice.

Similarly, Emil (42) explained feeling rewarded for passing on the lessons he has learned to young people:

I heard about STR8 UP and I remember hearing someone say that you go talk to schools. You go talk to kids. I remember them saying that it was ex-gang members talking about how their lives changed with drinking and alcohol. I thought that I would like to be a part of that. It would be good. It would be some sort of good for humanity. If I could tell my story and some kid would turn away from the life of gangs.

It is through their connections to the streets and their lived experiences that the men in this study can shift the community opinions about Indigenous street gangs. The men's narratives are what make this research relevant as their stories need to be used to inform policy and 
support effective prevention and intervention programs such as STR8 UP. This leads directly into the next phase, which is the notion of reciprocity or giving back to the community.

\section{Reciprocity - Appropriating Knowledge Transfer and Mobilization}

One of the most precarious barriers in research is that of knowledge power or whose knowledge is seen as dominant, as it shapes the selective process on determining what knowledge is to be valued (Friere, 1970). Western colonial knowledge is positioned as objective truth and thus other knowledges have been subjugated and analyzed through its perspectives (Smith, 1999; Louis, 2007; Denzin et al., 2008; Kovach, 2009). However, following the work of feminist, anti-racist, and critical scholars, research has begun to center the experiences of others as legitimate and valid (Castleden et al., 2008). To dismantle barriers created through colonization,

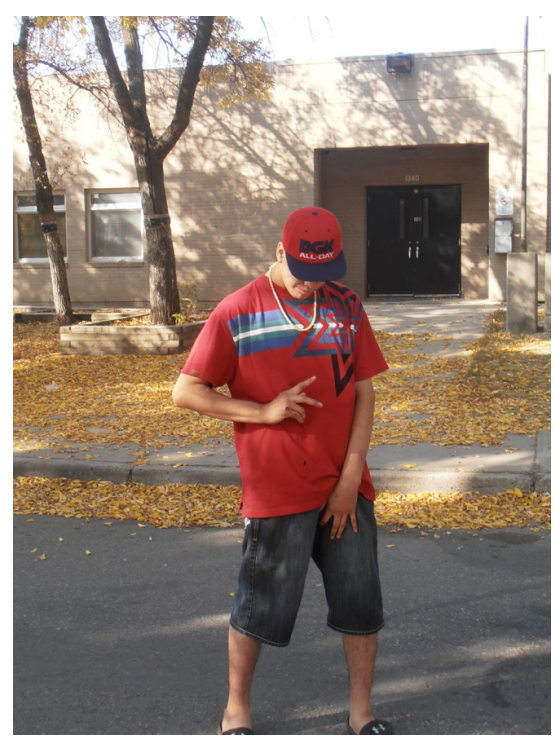

Figure 4: Dave and Robert went to Dave's old neighborhood in Regina to take a photo of it. There three members of the Native Syndicate Killers (NSK), one of Dave's old rival gangs, approached them. Seeing him as a threat since he was wearing all black clothing, they challenged Dave's identity and masculinity. After some tense moments, the three men saw that Dave and Robert were not a threat. One even posed for Dave for a photo, which was used as the cover of Brighter Days Ahead. The individual posing had asked to be on the cover of any book that was produced. concepts of reciprocity can remind researchers that "all research is appropriation" (Rundstrom \& Deur, 1999) researchers and participants should ensure that participation benefit either directly or indirectly from research (Louis, 2007).

Reciprocity with Indigenous peoples is more than just acknowledging ownership of one's knowledge. It is also about recognizing that knowledge must be "gifted" (Koukkanen, 2007). Traditionally and culturally for many Indigenous peoples of the Prairies, this was done through the gifting of tobacco when one inquires of an Elder for knowledge or advice. Most often, reciprocity comes in the form of monetary honorariums or gifts (Swartz, 2011). For this study, participants were given $\$ 40$ for each interview as well as digital cameras for them to take their photographs.

Participants were cautious in their participation during the research process; this can be attributed to their socialization (parents, peers, street codes) and past experiences with individuals outside of their community. They were socialized not to trust individuals who were not from their community or those that they did not have relationships with. For example, Larry (31) explained that when he was growing up:

....anything that had to do with, let's just put it bluntly — white people — back then, anything that had to do with white people you never trusted 
them you stay away from them.

Therefore, the men exercised caution as a way to analyze the benefits in relation to the cost of the information that they were giving. The concept of caution that the men expressed leads into the final phase of the relational accountability: responsibility.

\title{
Responsibility - Researcher and Participant Accountability
}

Responsibility within an academic research context has shifted over the last twenty-five years, when "there has been a trend toward demanding that universities be accountable to government and to society as a whole" (Kuokkanen, 2007, p. 113). In a historical context, research within Indigenous communities has often lacked accountability to the community (Smith, 1999; Kovach, 2009) and Indigenous knowledge at times has been used by colonial governments to exert control over Indigenous peoples themselves (Battiste, 2008; Denzin \& Lincoln, 2008). The research landscape with Indigenous peoples has changed considerably in Canada with the Tri-Council Policy Statement (TCPS 2) and OCAP (Ownership, Control, Access, and Possession) principles being discussed in university ethic committees. At the university level, checks and balances are used to ensure the safety of the researcher and the research participants, and that the research is within the standards set by TCPS2, including research with Indigenous peoples. However, approval by university ethics boards does not give researchers the privilege to conduct research in Indigenous communities. Often this privilege is earned over time through the building of relationships with Indigenous partners.

Responsibility is found through all aspects of the research framework. Therefore, it is difficult to ascertain that responsibility is only a phase within the process. However, it is the final process binds a relational research framework:

\begin{abstract}
Responsibility links consciousness with conscience. It is not enough to merely know one's responsibilities; one must also be aware of the consequences of one's actions. Without this awareness, there is a risk of the arrogance of a "clean conscience," a stance of studied innocence by privileged, hegemonic academics who can afford to be indifferent and not-knowing. (Kuokkanen, 2007, p. 115)
\end{abstract}

It is through responsibility that relational accountability shifts research from just knowledge gathering and reproduction of knowledge, to a sense of agency that shapes the development of policy and ethical change for communities.

Those researchers who work with Indigenous communities must be responsible with the knowledge that they have gained, mobilize it in ways that create positive change, and support agencies for change (Smith, 1999; Castleden et al, 2008; Denzin et al., 2008), or what Paul Farmer (2003) views as pragmatic solidarity. It is in this movement from knowledge of facts to knowledge for agency that a shift in the political nature of research can occur. As Rauna Kuokkanen (2007) states: 
Information amounts to little more than a collection of facts; knowledge is the result of the ability to learn and perceive. For information to become knowledge, one must do something with it. There can be no responsibility in the academy when there is merely information. Besides knowledge, responsibility requires action. (p. 114)

In other words, if it is not helping the community, or the community cannot use the information because it is not accessible, than what good is the research for the community? Responsibility is integral in the development and maintenance of relational accountability. Responsibility strengthens relationships by showing commitment and ethical conduct during the research. Post-research, responsibility allows researchers and participants to maintain their relationships, knowing that the knowledge will be used in a good way.

Responsibility was integral in this project due to the current and historical relationships that participants had with settler colonials and colonial institutions. To maintain ethical responsibility of the collected information, participants were informed that they would have the opportunity to remove any information from their transcripts. This was important because the focus of the interviews was to collect their life stories and those specific experiences that led them to become involved in a street gang. Because of the secrecy surrounding street gangs and the negative label of the 'informant', ${ }^{1}$ it was important that participants had the opportunity to remove any names of street gangs or gang members so that they would not be viewed negatively in the community.

A second way that responsibility was taken into account was the use of pseudonyms for the men. The choice to use a pseudonym was offered because some of the men wanted people to know who they were, while others wanted to use their street names because of what those names meant to them. When we offered the choice, the men were able to maintain a level of ownership of their knowledge.

Finally, regarding the photographs, participants were reminded that due to privacy laws, they had to be responsible and inform others if they were going to takepictures of other people and why they were taking them. To gain permission to photograph others, participants were given photograph release forms and were instructed that they had to inform others about the project and its intentions. Thus, the participants also became responsible agents within the process, as they needed to be consciously aware of the impacts that their actions could have on others.

When responsibility becomes a core feature of a research project, it binds together the agency needed to make positive change within communities. It helps researchers with reflexivity and helps them to understand that their work does not end after the project. Rather, responsibility helps to maintain relationships for future research opportunities because the researcher will be remembered as having done the research in a good way.

\footnotetext{
1 This label has extreme negative connotations for individuals as the label can severely impact their status within street fields.
}

Engaged Scholar Journal: Community-Engaged Research, Teaching and Learning 


\section{Conclusion}

As we reflected on the methodological processes that were undertaken for this project, we realized the extent to which relational accountability guided the research process. When research relationships are constructed through an ethical lens, researchers have the opportunity to create a space of critical reflexivity. Questioning oneself by asking: "Why am I doing this research?" "Why am I using these methods?" or "Is my research even relevant?" is important because such questions help the researcher to begin to create a critical self-reflexive gaze. Through critical reflection, researchers have the opportunity to "unlearn" how they have been socialized to see the world, and open it up for new ways of interpretation (Danius, Jonsson, \& Spivak, 1993; Spivak, 2011). This critical self-reflection is important when conducting research with Indigenous peoples in Canada, as it allows non-Indigenous and Indigenous researchers to critically assess their social privileges and biases constructed through Canadian socio-political histories that have been framed through colonization.

Through previously established relationships with STR8 UP, the recruitment of a cohort of Indigenous male ex-gang members who had participated in street gangs across the Prairie Provinces was attainable in a short time period. Relationships with Father André and Stan helped to build trust with the men, as both are well respected by STR8 UP members and the broader street community. Once we had gained their respect, participants were more open to the possibility of opening up about their experiences.

As the research progressed, specific attention was given to the ways that ethical space between researcher and participants were created. By carrying out their research within a framework of relationality, researchers had the opportunity to reflect on their spaces of privilege. By understanding how social spaces of privilege shape relationships with marginalized populations, both researcher and participant alike can work together to break down barriers that promote privilege and division (race, class, gender). For example, on conclusion of the research, the participants were asked to reflect on their first meeting with Robert. The majority stated that upon first meeting Robert, they thought, "What the hell does this white boy want from me?" As a result of colonial histories of violence and control, it was necessary for Robert, even as an Indigenous person, to understand how his white-skin privilege had shaped his experiences, opportunities, and social capital. Thus, over the course of the research project, Robert needed to come to terms with his own privileges and personal history, and become aware of how they impacted the research relationships and the research process itself.

Relational accountability is a process, and it is within this process that respect, relevance, reciprocity, and responsibility intersect to strengthen research partnerships. The process of relational accountability is important as it helps researchers and Indigenous community partners to create ethical boundaries, expectations, and fluidity that can benefit all those involved. Relational accountability provides Indigenous partners the potential to be involved in the research process in an effort to create and support a Frierian space of collaborativetransformational pedagogy and agency (Friere, 1970). Research through a Frierian perspective shifts the historical research perspective from researcher as knower to researcher as learner.

For Indigenous researchers and communities, a relational accountability framework 
allows for stronger connections to community agency for improved wellbeing. Indigenous epistemologies are built from relationships, relationships to land, time, self, and space. Relational accountability as a paradigm then is the key to community-engaged ethically sound research. Because the model here is not framed within cultural appropriation (the adding of a culture to make it relevant), it is easily adaptable to Indigenous and non-Indigenous knowledge frameworks in a global context. A relational accountability research framework provides a roadmap for junior and senior researchers to follow in efforts to improve relationships between Indigenous and settler nations to decolonize minds and create spaces of opportunity for all.

\section{About the Authors}

Robert Henry (corresponding author) is Métis from Prince Albert, SK and is an Assistant Professor in the Department of Sociology, University of Calgary. Robert's research areas include Indigenous street gangs and gang theories, Indigenous masculinities, Indigenous and critical research methodologies, youth mental health, and visual research methods. Working closely with community partners, he published a collection of narratives from his $\mathrm{Ph} . \mathrm{D}$. research titled Brighter Days Abead (2014). Robert has also published in the areas of masculinity, Indigenous health, youth subcultures, and criminal justice. Email: robert.henry1@ucalgary.ca

Caroline Tait is a Saskatchewan-born Métis researcher and is an Associate Professor in the Department of Psychiatry, University of Saskatchewan. Dr. Tait is trained in medical anthropology and life history methods. After completing graduate studies in new reproductive technologies at University of California (Berkeley, California) and doctoral and postdoctoral studies in social and transcultural psychiatry at McGill University (Montreal, Quebec). Dr. Tait is also the Co-lead of the First Peoples - First Person Indigenous Hub, aligned with the Canadian Depression Research Institute Network.

STR8 UP, 10,000 Steps to Healing Inc., is a non-profit community-based organization in Saskatoon that focuses on supporting individuals who are exiting the street gang lifestyle. STR8 UP focuses its program within a holistic approach through the use of the Medicine Wheel, where healing from trauma and addictions becomes the focal point for change. STR8 UP has provided over 1000 presentations across Saskatchewan to educate youth, community members, policy-makers, and frontline workers on the realities of those who find themselves involved in a street gang lifestyle. 


\section{References:}

Absolon, K. E. (2011). Kaandosswin: How we come to know. Black Point, Nova Scotia: Fernwood Publishing.

Alfred, T. (2005) Wasase: Indigenous pathways of action and freedom. Ontario, Canada: University of Toronto Press.

Barrows, J., \& Huff, C. R. (2009). Gangs and public policy. Criminology \& Public Policy, 8(4), 675-703.

Bjerregaard, B. (2003). Antigang legislation and its potential impact: The promises and the pitfalls. Criminal Justice Policy Review, 14(2), 171-192.

Blodgett, A. T., Schinke, R. J., Smith, B., Peltier, D., \& Pheasant, C. (2011). In Indigenous words: Exploring vignettes as a narrative strategy for presenting the research voices of Aboriginal community members. Qualitative inquiry, 17(6), 522-533.

Bourgois, P. (2009). In search of respect: Selling crack in El Barrio, Second Edition. UK: Cambridge University Press.

Bracken, D. C., Deane, L., \& Morrissette, L. (2009). Desistance and social marginalization: The case of Canadian aboriginal offenders. Theoretical Criminology, 13(1), 61-78.

Brooks, C., Poudrier, J., \& Thomas-MacLean, R. (2008). Creating collaborative visions with aboriginal women: A photovoice project. In P. Liamputtong (Ed.) Doing Cross-Cultural Research (pp. 193211). Netherlands: Springer

Brown, L., \& Strega, S. (2005). Research as resistance: Critical, indigenous and anti-oppressive approaches. Toronto, Ontario: Canadian Scholars' Press.

Cacho, L. M. (2012). Social death: Racialized rightlessness and the criminalization of the unprotected. NYU Press.

Castellano, M.B. (2004). Ethics of aboriginal research. Journal of Aboriginal Health, 98-114.

Castellano, M. B. (2000). Updating aboriginal traditions of knowledge. Indigenous knowledges in global contexts: Multiple readings of our world, edited by George Sefa Dei et al. Toronto: University of Toronto Press, 21-36.

Castelden, H., \& Gavin, T. Huu-ay-aht First Nation.(2008). Modifying photovoice for communitybased participatory research. Social Science and Medicine, 66, 1393-1405.

Castleden, H., Morgan, V. S., \& Lamb, C. (2012). "I spent the first year drinking tea": Exploring Canadian university researchers' perspectives on community-based participatory research involving Indigenous peoples. The Canadian Geographer/Le Géographe canadien, 56(2), 160-179.

Comack, E., Deane, L., Morrissette,L., \& Silver, J. (2013). Indians wear red: Colonialism, resistance, and aboriginal street gangs. Fernwood Publishing.

Criminal Intelligence Service Saskatchewan (CISS). 2005. Intelligence trends: Aboriginal based gangs in Saskatchewan. Regina: Government of Saskatchewan, 2005.

Danius, S., Jonsson, S., \& Spivak, G. C. (1993). An interview with Gayatri Chakravorty Spivak. Boundary 2, 24-50.

Dei, G. J. S., Karumanchery, L. L., \& Karumanchery, N. (2004). Playing the race card: Exposing white power and privilege (Vol. 244). Peter Lang.

Denzin, N. K., \& Lincoln, Y. S. (2008). Introduction: Critical methodologies and Indigenous inquiry. In N.K. Denzin, Y.S. Lincoln \&. L.T. Smith (Eds.) Handbook of critical and Indigenous methodologies (pp. 1-20) Thousand Oaks, US: Sage Publications. 
Doyle, A., \& Moore, D. (2011). Introduction: Questions for a new generation of criminologists. Critical criminology in Canada: New voices, new directions (pp. 1-24). Canada: UBC Press.

Ermine, W. (2007). The ethical space of engagement. Indigenous Law Journal, 6(1), 193-203.

Farmer, P. (2004). Pathologies of power: Health, human rights, and the new war on the poor (Vol. 4). Oakland, California: University of California Press.

Flanagan, T. (2008). First Nations? Second thoughts. McGill-Queen's Press-MQUP.

Francis, D. (1992). The imaginary Indian: The image of the Indian in Canadian culture. Arsenal Pulp Press.

Freire, P. (1970). Pedagogy of the oppressed. New York, London: Continuum.

Garot, R. (2010). Who you claim: Performing gang identity in school and on the streets. NYU Press.

Grande, S. (2004). Red pedagogy: Native American social and political thought. Rowman \& Littlefield.

Grekul, J., \& LaBoucane-Benson, P. (2008). Aboriginal gangs and their (dis) placement:

Contextualizing recruitment, membership, and status. Canadian Journal of Criminology and Criminal Justice, 50(1), 59-82.

Hart, M. A. (2010). Indigenous worldviews, knowledge, and research: The development of an Indigenous research paradigm. Journal of Indigenous Voices in Social Work, 1(1), 1-16.

Henry, R. (2013). Moving beyond the simple: Addressing the "misuse" of the FASD-Gang Link in Public Discourse. Pimatisinin, 11(2), 241-254.

Innes, R. A. (2009). “Wait a second. Who are you anyways?”: The Insider/Outsider debate and American Indian Studies. The American Indian Quarterly, 33(4), 440-461.

King, M., Smith, A., \& Gracey, M. (2009). Indigenous health part 2: The underlying causes of the health gap. The Lancet, 374(9683), 76-85.

Kirkness, V. J., \& Barnhardt, R. (1991). The Four R’s-Respect, Relevance, Reciprocity, Responsibility. Journal of American Indian Education, 30(3), 1-15.

Kirmayer, L., Simpson, C., \& Cargo, M. (2003). Healing traditions: Culture, community and mental health promotion with Canadian Aboriginal peoples. Australasian Psychiatry, 11(sup1), S15-S23.

Klein, M. W., \& Maxson, C. L. (2010). Street gang patterns and policies. Oxford University Press.

Kleinman, A. M. (1977). Depression, somatization and the "new cross-cultural psychiatry". Social Science \&o Medicine (1967), 11(1), 3-9.

Kontos, L., Brotherton, D. C., \& Barrios, L. (2005). Gangs and society. Columbia University Press.

Korp, P. (2008). The symbolic power of 'healthy lifestyles'. Health Sociology Review, 17(1), 18-26.

Kovach, M. E. (2010). Indigenous methodologies: Characteristics, conversations, and contexts. University of Toronto Press.

Kuokkanen, R. J. (2007). Reshaping the university: Responsibility, Indigenous epistemes, and the logic of the gift. Vancouver: UBC Press.

LaRocque, E. (2011). When the other is me. Winnipeg, Manitoba: University of Manitoba Press.

Lavallee, L. F. (2009). Practical application of an Indigenous research framework and two qualitative Indigenous research methods: Sharing circles and Anishnaabe symbol-based reflection. International Journal of Qualitative Methods, 8(1), 21-40.

LaVeaux, D., \& Christopher, S. (2009). Contextualizing CBPR: Key principles of CBPR meet the Indigenous research context. Pimatisiwin, 7(1), 1.

Macdougall, B. (2011). One of the family: Métis culture in nineteenth-century northwestern Saskatchewan. UBC Press. 
Messerschmidt, J. W. (2004). Flesh and blood: Adolescent gender diversity and violence. Rowman \& Littlefield Publishers.

Mitchell, C. (2011). Doing visual research. Thousand Oaks, US: Sage Publications

Nussbaum, S. (2015). American cultural baggage: How to recognize and deal with it. New York: Orbis Books.

Omi, M., \& Winant, H. (2014). Racial formation in the United States. UK: Routledge.

Omi, M., \& Winant, H. (1993). On the theoretical status of the concept of race. Race, Identity and Representation in Education (pp. 3-10). Canada: AbeBooks

O’Reilly-Scanlon, K., Crowe, C., \& Weenie, A. (2004). Pathways to understanding: "Wahkohtowin" as a research methodology. McGill Journal of Education/Revue des sciences de l'éducation de McGill, 39(1), 29-44.

Razack, S. (2015). Dying from improvement: Inquests and inquiries into Indigenous deaths in custody. Toronto, Canada: University of Toronto Press.

Rios, V. M. (2011). Punished: Policing the lives of Black and Latino boys. New York, US: New York University Press.

Rundstrom, R., \& Deur, D. (1999). Reciprocal appropriation. In J.D. Proctor \& D.M. Smith (Eds.), Geography and Ethics: Journeys in a Moral Terrain (237-250). New York: Routledge.

Sensoy, Ö., \& DiAngelo, R. (2012). Is everyone really equal?: An introduction to key concepts in social justice education. US: Teachers College Press.

Simpson, Leanne. "Anishinaabe ways of knowing." Aboriginal health, identity, and resources (2000), 165185.

Sinclair, R. (2012). Aboriginal youth gangs in Canada:(de) constructing an epidemic. First Peoples Child \& Family Review, 7(1), 8-28.

Smith, L. T. (1999). Decolonizing methodologies: Research and indigenous peoples. Winnipeg: Zed Books.

Spergel, I. A. (1995). The youth gang problem: A community approach. New York: Oxford University Press.

Spivak, G. C. (1988). Can the subaltern speak? In C. Nelson \& L. Grossberg (Eds.), Marxism and the Interpretation of Culture (271-313). Chicago: University of Illinois Press.

Spivak, G. C. (2011). An aesthetic education in the era of globalization. Cambridge, MA: Harvard University Press.

Swartz, S. (2011). 'Going deep'and 'giving back': strategies for exceeding ethical expectations when researching amongst vulnerable youth. Qualitative Research, 11(1), 47-68.

Totten, M. (2010). Investigating the linkages between FASD, gangs, sexual exploitation and woman abuse in the Canadian Aboriginal population: A preliminary study. First Peoples Child \& Family Review, 5(2), 9-22.

STR8 UP. (2012). STR8 Up and gangs: The untold stories. Saskatchewan, Canada: Hear My Heart Books.

Van Hofwegen, S. L. (2009). Unjust and ineffective: A critical look at California's Step Act. Southern California Interdisciplinary Law Journal, 18, 679-703.

Venkatesh, S. A. (2008). Gang leader for a day: A rogue sociologist takes to the streets. US: Penguin.

Vervoort, P. (2004). Edward S. Curtis's "Representations": Then and Now. American Review of Canadian Studies, 34(3), 463-484.

Wang, C. (2003). Using photovoice as a participatory assessment and issue selection tool. Community based participatory research for health (pp. 179-196). Canada: Wiley

Wang, C., \& Burris, M. A. (1997). Photovoice: Concept, methodology, and use for participatory needs assessment. Health education \& behavior, 24(3), 369-387. 
Wang, C. C., Cash, J. L., \& Powers, L. S. (2000). Who knows the streets as well as the homeless? Promoting personal and community action through photovoice. Health Promotion Practice, 1(1), 81-89.

White, R. (2008). Disputed definitions and fluid identities: The limitations of social profiling in relation to ethnic youth gangs. Youth Justice, 8(2), 149-161.

White, R. (2013). Youth gangs, violence and social respect: Exploring the nature of provocations and punch-ups. UK: Palgrave Macmillan.

Widdowson, F., \& Howard, A. (2008). Disrobing the Aboriginal industry: The deception behind Indigenous cultural preservation. Montreal: McGill-Queen's University Press.

Wilson, S. (2008). Research is ceremony: Indigenous research methods. Fernwood Publishing. 